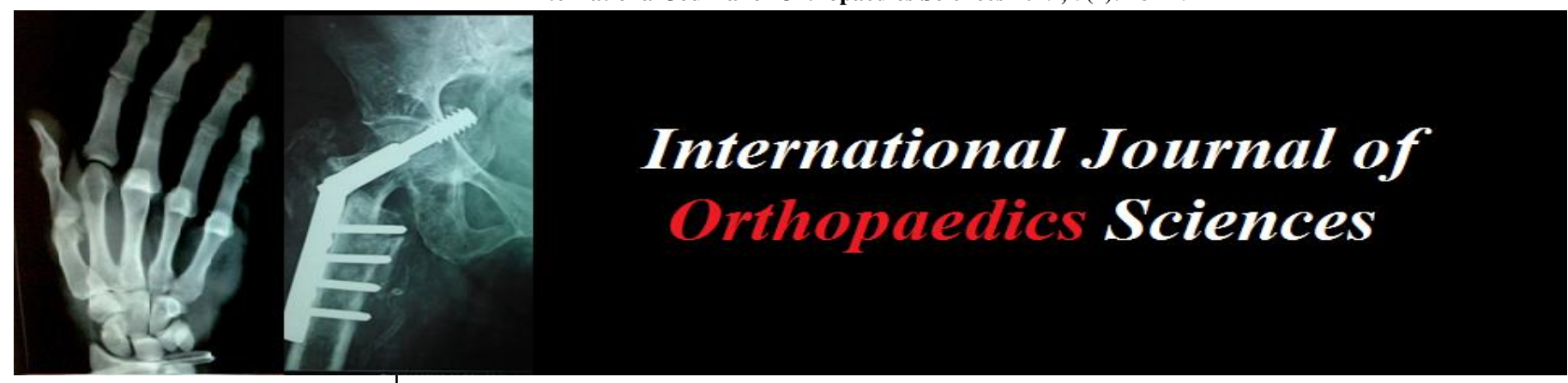

ISSN: 2395-1958

IJOS 2019; 5(2): 787-792

(C) 2019 IJOS

www.orthopaper.com

Received: 01-02-2019

Accepted: 05-03-2019

Dr. Sudhir KAM Shandilya Professor, Department of Orthopaedics ASRAM Medical College and General Hospital, Malakapuram, Eluru, Andhra Pradesh, India

Dr. Srinaresh Karna Irrinki Associate Professor, Department of Orthopaedics ASRAM Medical College and General Hospital, Malakapuram, Eluru, Andhra Pradesh, India
Correspondence

Dr. Srinaresh Karna Irrinki

Associate Professor, Department of Orthopaedics ASRAM Medical College and General Hospital, Malakapuram, Eluru, Andhra Pradesh, India

\section{Various methods of surgical management and its utility in proximal humerus fractures: A prospective study of 30 cases}

\author{
Dr. Sudhir KAM Shandilya, Dr. Srinaresh Karna Irrinki
}

DOI: https://doi.org/10.22271/ortho.2019.v5.i21.91

Abstract

Background: Treatment of fractures of proximal humerus has been a subject of much controversy and confusion with diversity of opinion regarding the management of fractures of proximal end of humerus. The aim of this study was to know the best modality of management of proximal humerus fracture in a defined patient group by reviewing the outcome, results and complications of the various operative procedures for fixation of proximal humerus fracture and their comparison in a series of thirty patients. METHODS: Over a two-year period, we treated thirty patients of two-part fractures and three-part fractures, with percutaneous pinning with $\mathrm{K}$-wires, cancellous screws, buttress plate (T/Clover leaf), and LCP. All patients underwent rigorous postoperative rehabilitation under the supervision of physiotherapist and functional outcome was assessed with the use of Neer's shoulder score. RESULTS: All fractures united within the first year and 1 patient had pin infection, 1 had loss of reduction, 3 cases malunion, 2 impingement and 1 case of AVN. The functional outcome of the assessment performed with Neer's score $57 \%$ of the cases had excellent results, $20 \%$ satisfactory results, $16 \%$ of them had unsatisfactory results and failure was seen in $7 \%$ of the cases. CONCLUSION: ORIF in adult patients with proximal humeral fractures reduces hospital-stay thereby preventing loss of earning and in elderly patients prevents reflex sympathetic dystrophy, stiffness and shoulder hand syndrome by early mobilization without any undue risk of loss of fixation and reduction.

Keywords: Proximal end of humerus, internal fixation, Neer's shoulder score

\section{Introduction}

Proximal humerus fractures are one of the commonest fractures (4-5\% of all fractures) occurring in in elderly patients due to senile osteoporosis ${ }^{[2,5,7]}$. However, these fractures are also seen in all age groups. The most serious fractures and fracture dislocations are in active, middle aged patients which can be extremely disabling and their management often demands experienced surgical skills and judgement ${ }^{[5]}$.

Increased high velocity trauma with resultant complex fracture pattern in proximal humerus are causing an enigma of management due to multiple deforming muscle forces and paucity of space for fixing implant in fracture of proximal humerus. The preferred treatment varies depending on the patient's age and bone quality, the expertise of surgical team and the patient's expectations.

The surgery should be carried out as soon as the patient's general condition permits. A delay of several days makes reduction more difficult and a significant delay, results in absorption of bone, making secure internal fixation impossible.

The objective of the osteosynthesis is to reduce the displaced fragment and hold it in place with an implant. The greater tuberosity is usually displaced proximally, rotated upward by supraspinatus, is placed properly and fixed to the major humeral head fragment. Similarly, lesser tuberosity fragment displaced by subscapularis is reduced and fixed. Three- \& four-part fractures represent 13 to $16 \%$ of proximal humeral fractures. Neer recommended ORIF for displaced two and three parts fractures. Most of the poor results of ORIF of three-part fracture are due to imperfect technique. In a three-or four-part fracture dislocations, because of possible AVN, head can be replaced by Neer's prosthesis. 
By this study, we want to establish if ORIF in adult patients with proximal humeral fractures reduces hospital-stay thereby preventing loss of earning and in elderly patients prevents reflex sympathetic dystrophy, stiffness and shoulder hand syndrome by early mobilization without any undue risk of loss of fixation and reduction.

\section{AIM}

To know the best modality of management of proximal humerus fracture in a defined patient group.

\section{Objectives}

1. Study different modalities of the fixations in proximal humerus fractures.

2. Compare the results using single scoring system.

3. Assess the functional outcome using Neer's scoring system.

\section{Patients and Methods}

This study was carried out in one of the private medical colleges of Andhra Pradesh from September 2016 to November 2018. Thirty patients of proximal humerus fractures who attended in the casualty/OPD were admitted and were treated surgically. Post-operatively, patients were followed up regularly.

\section{Inclusion Criteria}

All adults with proximal humerus fractures. [Neer's classification: grade 2 and grade 3 ]

\section{Exclusion Criteria}

1. Medically unfit patients

2. Pathological fractures

3. Fractures in pediatric age group

4. Shaft humerus fractures with proximal extension

5. Neer's one-part fracture

Fractures were evaluated in a standard way and classified according to the Neer's classification. Initial temporary immobilization with shoulder immobilizer/U Slab \& Bandage was done.

With routine pre-operative investigations and complete medical and anesthetic fitness, patients were subjected to surgery. Modality of surgical treatment was decided based on following factors.

1. Neer's classification.

2. Presence of shoulder dislocation, humeral head comminution

3. Valgus impaction

4. Comminution

5. Quality of bone

6. Open or compound fracture

7. Age of the patient

8. Associated general and medical condition of the patient

9. Other associated lesions e.g. brachial plexus palsy

10. Functional requirements of the patient

\section{The functional outcome}

It was evaluated using the Neer's Shoulder Scoring System.

\section{Method of surgical treatment}

1. CRIF with $\mathrm{K}$ - wire.

2. CRIF with Percutaneous Screw.

3. ORIF with various implants e.g. Buttress plate, Locking compression plate.
Indication for Crif with percutaneous fixation ${ }^{[6,8]}$.

1. Undisplaced two- or three-part fractures (displacement $<1 \mathrm{~cm}$ and angulation $<45^{\circ}$ )

2. Uncomminuted fractures.

3. Stable Closed reduction possible.

4. Glenohumeral Congruity present.

5. Poor GC requiring short procedure for Anesthetic reasons.

6. Valgus impacted fracture without lateral displacement

\section{Contraindications for Crif using percutaneous fixation}

1. Severely displaced fractures

2. Comminuted fractures

3. Irreducible two- or three-part fractures

4. Fractures involving splitting of the articular surface of the Humeral head
Indications for Orif ${ }^{[6]}$ :
1. Young age
2. Intact humeral head
3. Good bone quality
4. An angulation $>45$ degree
5. Displacement $>1 \mathrm{~cm}$

\section{Contraindication for Orif}

1. Open fracture

2. Presence of severe head comminution

\section{Functional assessment key}

Post-operative results were assessed using Neer's scoring as follows

Neers Scoring System 4

\begin{tabular}{|c|c|}
\hline PAIN & $\begin{array}{c}\text { Total 35 } \\
\text { Units }\end{array}$ \\
\hline A. No Pain & 35 \\
\hline B. Slight or Occasional & 30 \\
\hline C. Mild, No effect in ordinary activity & 25 \\
\hline D. Moderate, tolerable, starting to affect ordinary activity & 15 \\
\hline E. Marked, serious limitation of ordinary activity & 5 \\
\hline Total Disablement & 0 \\
\hline
\end{tabular}

Functional Ability Total 30 Units

\begin{tabular}{|c|c|c|c|c|c|}
\hline \multicolumn{2}{|c|}{ Strength } & \multicolumn{2}{c|}{ Reaching } & \multicolumn{2}{c|}{ Stability } \\
\hline Normal & 10 & Above head & 2 & Lifting & 2 \\
\hline Good & 8 & Mouth & 2 & Throwing & 2 \\
\hline Fair & 6 & Belt buckle & 2 & Carrying & 2 \\
\hline Poor & 4 & Opposite axilla & 2 & Pushing & 2 \\
\hline Trace & 2 & Brassiere Hook & 2 & Hold Overhead & 2 \\
\hline Zero & 0 & & & & \\
\hline
\end{tabular}

Range of Motion: Total 25 Units

\begin{tabular}{|c|c|c|c|c|c|c|c|c|c|}
\hline $\begin{array}{c}\text { Flexion } \\
\text { Scoring }\end{array}$ & \multicolumn{2}{|c|}{$\begin{array}{c}\text { Extension } \\
\text { Scoring }\end{array}$} & \multicolumn{2}{c|}{$\begin{array}{c}\text { External } \\
\text { Rotation } \\
\text { Score }\end{array}$} & \multicolumn{2}{c|}{$\begin{array}{c}\text { Internal } \\
\text { Rotation } \\
\text { Score }\end{array}$} & \multicolumn{2}{c|}{$\begin{array}{c}\text { Abduction } \\
\text { Score }\end{array}$} \\
\hline $180^{\circ}$ & 6 & $45^{\circ}$ & 3 & $60^{\circ}$ & 5 & $90^{\circ}$ & 5 & $180^{\circ}$ & 6 \\
\hline $170^{\circ}$ & 5 & $30^{\circ}$ & 2 & $30^{\circ}$ & 3 & $70^{\circ}$ & 4 & $170^{\circ}$ & 5 \\
\hline $130^{\circ}$ & 4 & $15^{\circ}$ & 1 & $10^{\circ}$ & 1 & $50^{\circ}$ & 3 & $140^{\circ}$ & 4 \\
\hline $100^{\circ}$ & 2 & $<15^{\circ}$ & 0 & $<10^{\circ}$ & 0 & $30^{\circ}$ & 2 & $100^{\circ}$ & 2 \\
\hline $80^{\circ}$ & 1 & & & & & & & $80^{\circ}$ & 1 \\
\hline$<80^{\circ}$ & 0 & & & & & & & $<80^{\circ}$ & 0 \\
\hline
\end{tabular}

Anatomy: Total 10 Units

Rotation, Angulation, Joint incongruity, Retracted Tuberosities, Non-union, AVN. 
- $\quad 10$

- Mild 8

- Moderate 4

- Severe $0-2$

These criteria were proposed by Neer. The maximum points are 100 units
1. Pain
35 Units
2. Function
30 Units
3. Range of Movement :
25 Units
4. Anatomy
10 Units

On overall scores, the patients were grouped into:

Results score

1. Excellent

2. Satisfactory

3. Un-Satisfactory

4. Failure

$>89$ units

80-89 units

70-79 units

$<70$

\section{Application of Biostatistics}

To compare results of our study with other standard studies we have used „Chi-Square ${ }^{\text {ee }}$ test. By using this test we have calculated $P$ value.

If $\mathrm{P}$ value is $>0.05$, the test result is not significant. That means the population of these two studies are not comparable. If $\mathrm{P}$ value is $<0.05$, the test result is significant. That means the population of these two studies are comparable.

\section{Observations and Result}

Age Incidence

Age variation in the series were from 20 to 65 years. Proximal humerus fractures were found to have high incidence in the 50 to 65 age group. The incidence of the study was as follows:

Table 1: Age incidence

\begin{tabular}{|c|c|}
\hline Age in years & Number of patients \\
\hline $20-30$ & 2 \\
\hline $31-40$ & 6 \\
\hline $41-50$ & 6 \\
\hline $51-60$ & 8 \\
\hline$>60$ & 8 \\
\hline Total & 30 \\
\hline
\end{tabular}

\section{Sex Incidence}

Table 2: Sex incidence

\begin{tabular}{|c|c|}
\hline Sex of patients & No of patients \\
\hline Male & 17 \\
\hline Female & 13 \\
\hline Total & 30 \\
\hline
\end{tabular}

There were 17 males (57\%) and 13 females (43\%) with male predominance.

\section{Side of Fracture}

Right sided was involved in more patients. 18 cases had right side involved. None had both the sides involved.

Table 3: Side distribution

\begin{tabular}{|c|c|}
\hline Side of injury & No of patients \\
\hline Right & 18 \\
\hline Left & 12 \\
\hline Total & 30 \\
\hline
\end{tabular}

Mode of Injury

Most of the injuries were caused by domestic fall due to minor slip or agricultural injury and another cause was road traffic accident due to vehicular accident specially in younger age group.

Table 4: Mode of injury

\begin{tabular}{|c|c|}
\hline Mode of injury & No of patients \\
\hline Domestic & 17 \\
\hline Vehicular & 13 \\
\hline Total & 30 \\
\hline
\end{tabular}

Mechanism of Injury

Various mechanisms of fracture in this study group are as shown in following table:

Table 5: Mechanism of Injury

\begin{tabular}{|c|c|}
\hline Mechanism of injury & No of patients \\
\hline Fall on outstretched hand (minor fall) & 13 \\
\hline High energy Trauma & 10 \\
\hline Excessive rotation of arm in abduction & 5 \\
\hline Direct blow & 2 \\
\hline Total & 30 \\
\hline
\end{tabular}

Closed or Compound Injury

Majority of the cases were closed except one compound fracture of Grade-1.

Table 6: Types of fractures

\begin{tabular}{|c|c|}
\hline Type of fracture & No of patients \\
\hline Closed & 29 \\
\hline Compound & 1 \\
\hline Total & 30 \\
\hline
\end{tabular}

Neer's Type of fracture: Two-part fractures constituted the most common type.

Table 7: Neer's type of fracture

\begin{tabular}{|c|c|c|}
\hline Neer's type & No. of patients & Percentage \\
\hline 2 part & 18 & $60 \%$ \\
\hline 3 part & 12 & $40 \%$ \\
\hline Total & & $100 \%$ \\
\hline
\end{tabular}

\section{Period between Injury and Surgery}

Most of the cases were operated between 1 to 3 days (27 cases) and remaining 3 cases were operated within $24 \mathrm{hrs}$. One of three was Grade 1 compound fracture

Table 8: Period between injury and surgery

\begin{tabular}{|c|c|c|}
\hline Time period & Number of patients & Percentage \\
\hline 0-6 Hours & 0 & $0 \%$ \\
\hline 6-24 Hours & 3 & $10 \%$ \\
\hline 1-3 days & 27 & $90 \%$ \\
\hline Total & 30 & $100 \%$ \\
\hline
\end{tabular}

\section{Types of Fixations}

Most proximal humerus fractures were fixed with open reduction (ORIF) and plate fixation. Others were treated with either close reduction and percutaneous $\mathrm{k}$-wires fixation $(\mathrm{CR}+\mathrm{P} / \mathrm{C} \mathrm{K}$ WIRES) or close reduction and percutaneous screws fixation $(\mathrm{CR}+\mathrm{P} / \mathrm{C}$ SCREWS $)$. 
Table 9: Fixation of Proximal humerus fractures

\begin{tabular}{|c|c|c|}
\hline Type of fixation & No of patients & Percentage \\
\hline CR+P/C K WIRES & 3 & $10 \%$ \\
\hline CR+P/C SCREWS & 2 & $7 \%$ \\
\hline OR+PLATE FIXATION & 25 & $83 \%$ \\
\hline Total & & $100 \%$ \\
\hline
\end{tabular}

\section{Immobilization}

Each operated patient was given a Universal shoulder immobilizer immediate post-operatively. The dressing was done accordingly at third and seventh day and the sutures were removed by twelfth day in open surgeries. The patient was also encouraged to exercise the hand, wrist and elbow. This is continued for six weeks. After 3 weeks k-wires were removed and pendulum exercises were started (In percutaneous $\mathrm{k}$-wire fixation method). In the 3 cases of open reduction and plate fixation, bone was severely osteoporotic so fixation was not so rigid, motion was delayed. Gentle passive forward flexion and internal and external rotation exercises were started by the third or fourth week. Active or resistive exercises were permitted by 4 to 6 weeks. It usually took about a year to achieve optimum function.

\section{Associated Injuries}

One patient had associated bicondylar tibial fracture. Remaining 29 patients had isolated fracture of proximal humerus.

\section{Complications}

Complications after Closed Reduction and K-wires Fixation

We encountered following two complications after CRIF with K-wire.

Table 10: Complications after closed reduction and k-wires fixation

\begin{tabular}{|c|c|c|}
\hline Complication & No of patients & Percentage \\
\hline Pin Infection & 1 & $33 \%$ \\
\hline Loss of reduction & 1 & $33 \%$ \\
\hline
\end{tabular}

\section{Complications after Orif with Plate}

Table 11: Complications of ORIF+PLATE fixation

\begin{tabular}{|c|c|c|}
\hline Complication & No of patients & Percentage \\
\hline Rotation of fragment intraoperatively & 3 & $12 \%$ \\
\hline Intra operative bleeding & 4 & $16 \%$ \\
\hline Malunion & 3 & $12 \%$ \\
\hline Impingement & 3 & $12 \%$ \\
\hline Avascular Necrosis & 2 & $8 \%$ \\
\hline
\end{tabular}

No complications observed with ce screw fixation. Union The mean period for Union was 10.46 weeks ranging from 8 12 weeks. There were no problems of delayed union or nonunion.

\section{End Result}

As per Neer's Scoring we have following END RESULTS in various treatment groups -

Table 12: End result of percutaneous k-wires fixation

\begin{tabular}{|c|c|c|}
\hline Grading & No of patients & Percentage \\
\hline Excellent & 1 & $33 \%$ \\
\hline Satisfactory & 1 & $33 \%$ \\
\hline Un- satisfactory & 1 & $33 \%$ \\
\hline
\end{tabular}

Table 13: End result of open reduction and plate fixation

\begin{tabular}{|c|c|c|}
\hline Grading & No of patients & Percentage \\
\hline Excellent & 14 & $56 \%$ \\
\hline Satisfactory & 5 & $20 \%$ \\
\hline Un- satisfactory & 4 & $16 \%$ \\
\hline Failure & 2 & $8 \%$ \\
\hline
\end{tabular}

$100 \%$ excellent results with percutaneous fixation with screws

\section{Overall results}

The overall results after using various surgical techniques were as shown in following table-

Table 14: Overall Results on basis of Neer's Scoring System

\begin{tabular}{|c|c|c|}
\hline Grading & No of patients & Percentage \\
\hline Excellent & 17 & $57 \%$ \\
\hline Satisfactory & 6 & $20 \%$ \\
\hline Un-satisfactory & 5 & $16 \%$ \\
\hline Failure & 2 & $7 \%$ \\
\hline
\end{tabular}

The results show that most Neer's two-part fracture had excellent to satisfactory results $(84 \%)$. Neer's three-part fracture also had $72 \%$ excellent to satisfactory results. In our series there was two cases of three-part fracture which went into failure was fixed with buttress plate (Table 15). The major reason for failures was avascular necrosis.

Table 15: Results according to Neer's different types of fracture on basis of Neer's Scoring System

\begin{tabular}{|c|c|c|c|c|c|}
\hline $\begin{array}{c}\text { Type of } \\
\text { Fracture }\end{array}$ & Total & Excellent & Satisfactory & Unsatisfactory & Failure \\
\hline 2 part & 18 & 11 & 4 & 3 & 0 \\
\hline 3 part & 12 & 6 & 2 & 2 & 2 \\
\hline
\end{tabular}

In our series 25 patients were treated by open reduction and plate fixation. In three cases reduction was difficult due to rotation of the fragments but it could be managed intraoperatively. Intra-operative bleeding was managed by adequate blood transfusion.

Three cases had abduction between $50^{\circ}-100^{\circ}$ due to malunion of the fracture fragment. Three patients fixed with cloverleaf plate had restricted range of movement due to impingement were treated with plate removal at 8 months when the fracture had united.

However, no impingement seen in the patients fixed with locking compression plate. Avascular necrosis in two patients was seen at follow up of 18 months and they went into failure.

\section{CASE 1}

ROM in a case of 2-part type 1 compound fracture treated with $\mathrm{CR}+\mathrm{P} / \mathrm{C} \mathrm{K}$ wire fixation

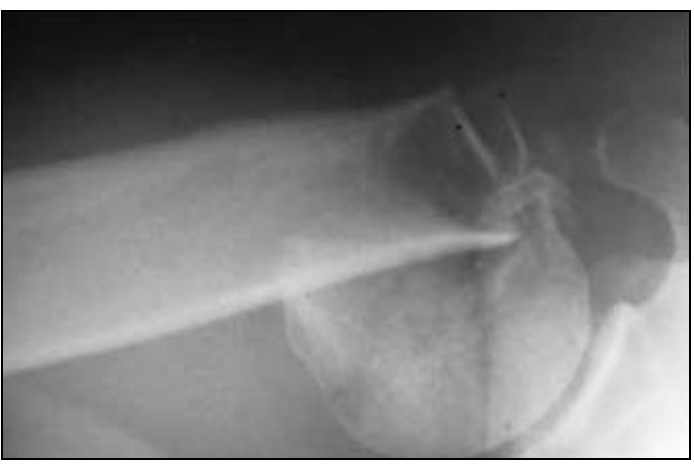

Axillary view showing 


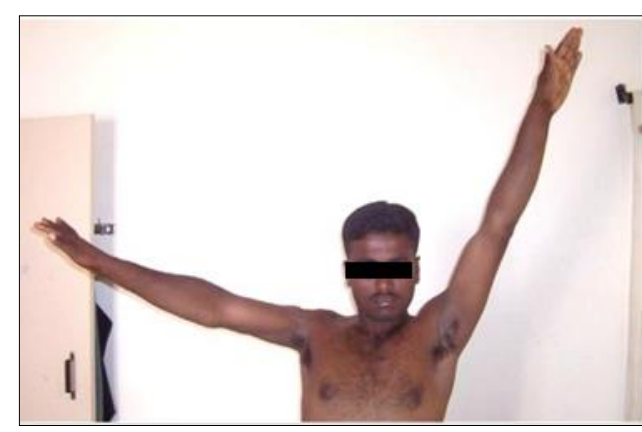

Abduction at follow up

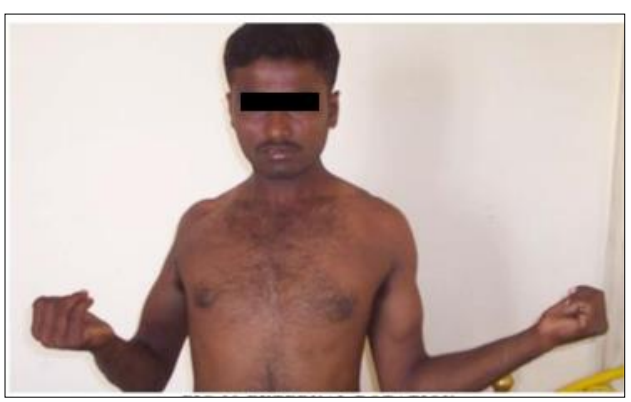

External Rotation at follow up

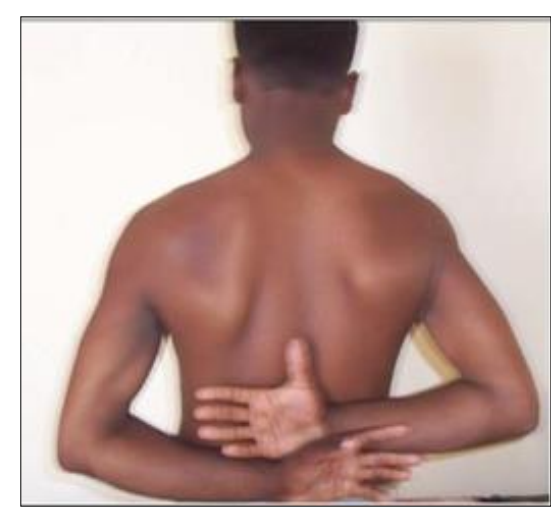

Internal Rotation at follow up

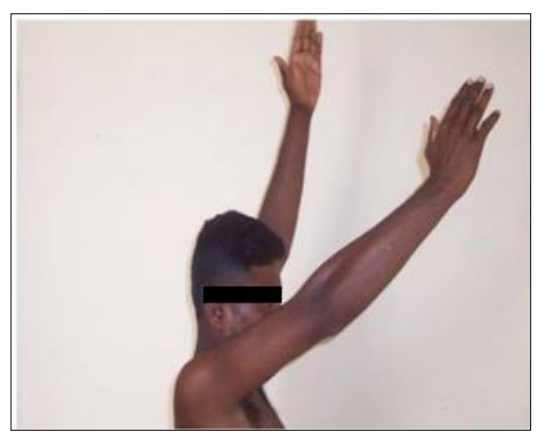

Forward flexion at follow up

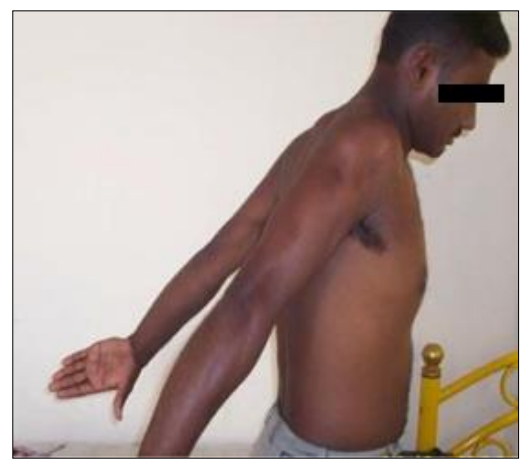

Extension at follow up

\section{Discussion}

There is increase in the occurrence of proximal humerus fractures in the last few years due to change in life style and also a proportionate increase in motor vehicle accidents. The best management of proximal humerus fractures is still uncertain. Studies have shown that both non-operative and operative treatments, both give favorable results, and hence uncertainty remains. However, with the aim of getting anatomically accurate reductions, rapid healing and early restoration of function, which is a demand of today's life, open reduction and internal fixation, is the preferred modality of treatment. It is to be noted that the risk of complications although is low after internal fixation, it is higher when compared with fractures which are managed percutaneously or conservatively.

The other options for treatment are

1. Non-operative: It is indicated in previous era. Function is as good as many of operative procedure because mostly are un-displaced.

2. Disadvantages: stiffness, non-union, osteonecrosis of humerus head

3. Minimally invasive k-wire/ screw fixation: Advantages: low soft tissue injury, low risk of infection

4. Disadvantages: less stable fixation, more chances of neurovascular injury, varus malalignment, immobilization of shoulder, less suitable in 3- part/ 4-part fractures, unable to repair rotator cuff injury, less suitable for fixation in osteoporotic bone.

\section{Intra medullary nailing}

Advantage: More stable fixation, less soft tissue injury, early mobilization

Disadvantage: Rotator cuff dysfunction in ante grade nailing, not indicated in multi-fragment fracture, indicated mainly in 2-part surgical neck Fracture.

Proximal humerus fractures occur more commonly in older age group. This is due to senile osteoporosis. Numerous agerelated studies point towards this and our study is consistent with this finding.

Table 16: Age related study pattern

\begin{tabular}{|c|c|c|}
\hline Study & $\begin{array}{c}\text { Age of patients } \\
\text { Studied }\end{array}$ & $\begin{array}{c}\text { Mean } \\
\text { age }\end{array}$ \\
\hline Roland P. Jacob ${ }^{[3]}$. & $24-81$ & 49.5 \\
\hline Gerber, C.M.L. Werner ${ }^{[10]}$. & $16-73$ & 44.9 \\
\hline Wijgman, W. Roolker ${ }^{[1]}$. & $19-79$ & 48 \\
\hline Evan L. Flatow, Francis Cuomo ${ }^{[9]}$. & $34-72$ & 53 \\
\hline P. Moonot, N. Ashwood, M. Hamlet ${ }^{[11]}$. & $18-87$ & 59.9 \\
\hline Present series & $21-70$ & 49.3 \\
\hline
\end{tabular}

Further as similar other studies, there is a higher incidence of fractures occurring in men than in women with gender ratio was 1.30: 1. This higher ratio can be explained by a higher involvement of male in day to day activities when compared to female.

Table 17: Gender related study pattern

\begin{tabular}{|c|c|}
\hline Study & M: $\mathbf{F}$ \\
\hline Roland P. Jacob $^{[3]}$. & 1.57 \\
\hline C.Gerber, C.M.L. Werner $^{[10]}$. & 1.35 \\
\hline Wijgman, W. Roolker $^{[1]}$. & 0.94 \\
\hline Evan L. Flatow, Francis Cuomo $^{[9]}$. & 1.40 \\
\hline Present series & 1.30 \\
\hline
\end{tabular}


The $\mathrm{P}$ value is $>0.05$ in all series according to Chi-square test which is not significant. Hence these study groups are comparable.

In our study, $57 \%$ of patients' domestic fall and $43 \%$ had vehicular accidents.

Eighteen patients had two-part fracture. At surgery more than $60 \%$ of them had soft tissue interposition at the fracture site. Two cases of greater tuberosity avulsion fracture (Two-part fracture) cancellous screws proved to be very effective in fracture fixation.

The case of grade-1 compound two-part fracture and two closed two-part fractures were treated with closed reduction and percutaneous k-wires fixation. Rest thirteen cases of twopart fracture were treated by open reduction and buttress plate fixation. Twelve patients had three-part fracture. Restoration of greater and lesser tuberosity was a particular difficulty in these cases (eight cases had surgical neck with greater tuberosity fracture and four had surgical neck with lesser tuberosity fracture). Ten of them were fixed with Cloverleaf plate, and rest two with Locking compression plate.

In our study, one case of three-part fracture was also having bicondylar tibia fracture, cause of injury was road traffic accident. He underwent a Locking compression plate for proximal humerus and simultaneously locking hockey stick plate for lateral condyle and L-plate for medial condyle tibia. Different studies, which have used the Neer's scoring system for assessment of results, demonstrate a fairly similar pattern of results with $70-80 \%$ patients having satisfactory to excellent results and $20-30 \%$ having un-satisfactory to failure results.

Table 18: Comparisons of result pattern with other study

\begin{tabular}{|c|c|c|}
\hline Result & Roland P. Jacob $^{[3]}$. & Present series \\
\hline Excellent & $21 \%$ & $57 \%$ \\
\hline Satisfactory & $53 \%$ & $20 \%$ \\
\hline Un- satisfactory & $10 \%$ & $16 \%$ \\
\hline Failure & $16 \%$ & $7 \%$ \\
\hline
\end{tabular}

The $\mathrm{P}$ value is $>0.05$ in all series according to Chi-square test which is not significant. Hence these study groups are comparable.

In our series $77 \%$ patients had satisfactory to excellent results and $23 \%$ had un-satisfactory to failure results. These results are comparable with the other study.

Our poor results have shown strong association with

Open injuries, which developed infection.

Three part severely displaced fracture in which articular head is devoid of soft tissue attachment which resulted into avascular necrosis of humeral head.

Results were consistently better in closed, less displaced twoand three-part fracture patterns.

\section{Follow up and Final Result}

In this study maximum period of follow up was 24 months and minimum of 6 months.

Open fracture was treated immediately by IV antibiotics, debridement and percutaneous k-wires fixation. He had infection, which did resolve with adequate treatment but gave satisfactory result.

\section{Conclusion}

ORIF in adult patients with proximal humeral fractures reduces hospital-stay thereby preventing loss of earning and in elderly patients prevents reflex sympathetic dystrophy, stiffness and shoulder hand syndrome by early mobilization without any undue risk of loss of fixation and reduction. Closed reduction and percutaneous cancellous screws fixation showed excellent results in undisplaced two-part greater tuberosity avulsion fracture. Open reduction and internal fixation with Locking compression plates showed good results among all implants used.

\section{References}

1. Wijgman AJ, Roolker W, Patt TW, Raaymakers el, Marti RK. Open reduction and Internal fixation of three and four-part fractures of the proximal part of the humerus. JBJS. 2002; 84(11):1919-25.

2. Elgohary HS, Selim NM. Locked plate fixation for proximal humerus fractures in elderly osteoporotic patients. The Egyptian Orthopedic Journal. 2013; 48(4):344.

3. Jakob RP, Ganz R. Proximal humerus fractures. Helvetica Chirurgica Acta. 1982; 48(5):595-610.

4. Paavolainen P, Björkenheim JM, Slätis P, Paukku P. Operative treatment of severe proximal humeral fractures. Acta Orthopaedica Scandinavia. 1983; 54(3):374-9.

5. Jain M, Mavani K. A comprehensive study of proximal humerus fractures and osteosynthesis in adult. International Journal of Orthopedics. 2016; 2(2):43-7.

6. Bucholz, Robert W, Heckman, James D, Court-Brown, Charles M. Rockwood \& Green's Fractures in Adults, 6th Edition-1181

7. Herscovici Jr D, Saunders DT, Johnson MP, Sanders R, DiPasquale T. Percutaneous fixation of proximal humeral fractures. Clinical Orthopedics and Related Research®. 2000; 375:97-104.

8. Kocialkowski A, Wallace WA. Closed percutaneous Kwire stabilization for displaced fractures of the surgical neck of the humerus. Injury. 1990; 21(4):209-12.

9. Cuomo F, Flatow EL, Maday MG, Miller SR, Mc ilveen SJ, Bigliani LU. Open reduction and internal fixation of two-and three-part displaced surgical neck fractures of the proximal humerus. Journal of shoulder and elbow surgery. 1992; 1(6):287-95.

10. Gerber C, Werner CM, Vienne P. Internal fixation of complex fractures of the proximal humerus. The Journal of bone and joint surgery. British. 2004; 86(6):848-55.

11. Moonot P, Ashwood N, Hamlet M. Early results for treatment of three- and four-part fractures of the proximal humerus using the PHILOS plate system. The Journal of bone and joint surgery. British. 2007; 89(9):1206-9. 